\title{
Parametric Optimization of Gas Metal Arc Welding Processes by Using Factorial Design Approach
}

\author{
Manoj Singla, Dharminder Singh, Dharmpal Deepak* \\ Department of Mechanical Engg., R.I.E.I.T.,Railmajra, 144533, INDIA \\ *Corresponding Author: manojsingla77@gmail.com
}

\begin{abstract}
Gas Metal Arc Welding is a process in which the source of heat is an arc format between consumable metal electrode and the work piece with an externally supplied gaseous shield of gas either inert such as argon, helium. This experimental study aims at optimizing various Gas Metal Arc welding parameters including welding voltage, welding current, welding speed and nozzle to plate distance (NPD) by developing a mathematical model for sound weld deposit area of a mild steel specimen. Factorial design approach has been applied for finding the relationship between the various process parameters and weld deposit area. The study revealed that the welding voltage and NPD varies directly with weld deposit area and inverse relationship is found between welding current and speed with weld deposit area.
\end{abstract}

Keywords: Gas Metal Arc Welding; Factorial Design Approach; Weld Deposit Area.

\section{INTRODUCTION}

Gas Metal Arc Welding is a process in which the source of heat is an arc format between consumable metal electrode and the work piece, and the arc and the molten puddle are protected from contamination by the atmosphere (i.e. oxygen and nitrogen) with an externally supplied gaseous shield of gas either inert such as argon, helium or an argon-helium mixture or active such as carbon dioxide, argon-carbon dioxide mixture, which is chemically active or not inert (Karadeniz et al. 2007). Initially GMAW was called as MIG Welding because only inert gasses were used to protect the molten puddle. The application of this process was restricted to aluminum, deoxidized copper and silicon bronze. Later it was used to weld ferrite and austenitic steels, and mild steel successfully by using active gasses in place of inert gasses and hence was term MAG (Metal Active Gas) welding (Suban and Tusek, 2003, Quinn et al. 1999).

The American Welding Society refers to the process Gas Metal Arc Welding process to cover inert as well as active shield gasses. GMAW is basically a semi automatic process, in which the 
arc lengths of electrode and the feeding of the wire are automatically controlled. The welding operator's job is reduced to positioning the gun at a correct angle and moving it along the seam at a controlled travel speed. Hence less operator skill is required with this process as compare to TIG and manual metal arc process. Yet basic training is required in the setting up of the equipment and manipulation of the gun must be provided to the operator to ensure quality GMAW welding (Jang et al. 2005, Praveen and Yarlagadda, 2005).

GMAW welding process overcome the restriction of using small lengths of electrodes and overcome the inability of the submerged-arc process to weld in various positions. By suitable adjusting the process parameters, it is possible to weld joints in the thickness range of 1-13 mm in all welding position (Kuk et al. 2004, Murugan and Parmar, 1994)

All the major commercial metals can be welded by GMAW $\left(\mathrm{MIG} / \mathrm{CO}_{2}\right)$ process, including carbon steels, low alloy and high alloy steels, stainless, aluminum, and copper titanium, zirconium and nickel alloys. (Quintino and Allum, 1981, Smati, 1985)

GMAW (MIG/CO $\left./ \mathrm{CO}_{2}\right)$ is also used in mechanized and automatic forms to eliminate the operator factor and to increase the productivity and consistency of quality.

\subsection{Mechanism of Metal Transfer in GMAW}

In the GMAW (MAG) process, the metal transfer from the electrode tip to the weld pool across the arc is either globular, spray type or short-circuiting type depending upon many factors, which are enlisted as follows:

- The magnitude of welding current

- Shielding gas

- Current density

- Electrode extension and

- Electrode chemistry

With $\mathrm{CO}_{2}$ shielding, the globular and non-axial, whatever may be the value of the welding current, current density and other factors. Hence there is considerable spatter. Drops become smaller in size as the current increases and they continue to be directed axially and non-axially.

Axial transfer means that the metal droplets move along a line that is an extension of the longitudinal axis of the electrode. Non-axial transfer means that the droplets are hurled in any other directions. The non-axial transfer is caused by electromagnetic repulsive force acting on the bottom of the molten drop. The electric current flowing through the electrode gives rise to several electromagnetic forces that act on the motel tip including the pinch force (p) and the anode reaction force $(\mathrm{R})$. The pinch force which increases with current and electrode diameter causes the drop to detach. With $\mathrm{CO}_{2}$ shielding, the electrode tip is not heated directly by the arc plasma but by the arc heat conducted through the molten drop. The molten drop grow in size and 
finally detaches by short circuiting or gravity, after having overcome the force $\mathrm{R}$, which tends to support the drop.

\subsection{Factorial Design Approach and Terminology}

Factorial experiments permits to evaluate the combined effect of two or more experiments variables when evaluated simultaneously. Information obtained from factorial experiments is more complete than those obtained from a series of single factor experiments, in the sense that factorial experiments permit the evaluation of interaction effects. An interaction effect is an effect attributable to the combination of variables above and beyond that which can be predicted from the variables considered separately.

For the need of factorial experiments, the information gathered could be used to make decisions, which have a board range of applicability. In addition to information about how the experiments variables operate in relative isolation, it can be predicted, what will happen when two or more variables are used in combination. Apart from the information about interactions, the estimate of the effects of the individual variables is a more practical use. In the case of factorial experiments, the population to which inferences can be made is more inclusive than the corresponding population for a single factor experiments. Factors may be classified as treatment and classification factors.

- Classification factors group the experimental units into classes which are homogeneous with respect to what is being classified.

- Treatment factors define experimental conditions applied to an experimental unit. The administration of the treatment factors is under the direct control of the experimenter, where as classification factors are not, in sense.

The effects of the treatment factors are of primary interest to the experimenter, where as classification methods are included in an experiment to reduce experimental error and clarify interpretation of the effects of the treatment factors.

The design of factorial experiments is concerned with answering the following questions:

- What factors should be included?

- How many levels of each factor should be included?

- How should the levels of the factors be spaced?

- How many experimental units should be selected for each treatment conditions?

- Can the effects of primary interests be estimated adequately from the experimental data that will be obtained?

A factor is a series of related treatments or related classifications. The related treatments making a factor constitute the levels of that factor. The number of levels within a factor is determined largely by the thoroughness with which an experimental desires to investigate the factor. 
Alternatively, the levels of a factor determined by the kind of inference the experimental desires to make upon a conclusion of experiment.

The dimensions of a factorial experiment are indicated by the number of levels of each factor. For the case of $\mathrm{p}^{*} \mathrm{q}$ factorial experiment, PQ different treatment combinations are possible. As number of factor increases, or as the number of levels with in a factor increases, the number of treatment combinations in a factorial experiment increases quite rapidly.

In an experiment, the elements observed under each of the treatment combinations will generally be a random sample from some specified population. This population may contain potentially infinite number of elements. If $\mathrm{n}$ elements are to be observed under each of treatment combination in $\mathrm{p}^{*} \mathrm{q}$ factorial experiment, a random sample of npq elements from population is required. The npq elements are then subdivide at random to the treatment combinations.

The $\mathrm{P}$ potential levels may be grouped in to $\mathrm{P}$ levels $(\mathrm{p}<\mathrm{q})$ by either combining adjoining levels or deliberately selecting what are considered to be representative levels.

When $\mathrm{p}=\mathrm{P}$ then the factor is called the fixed factor. When the selection of the p levels from the potential $\mathrm{P}$ levels is determined by some systematic, non-random procedure, then also the factor is considered a fixed factor. In this later case, the selection procedure, reduce the potential $\mathrm{P}$ levels to $\mathrm{p}$ effective levels .Under this type of selection procedure, the effective, potential number of levels of factor in the population may be designated as $\mathrm{P}_{\text {effective }}$ and $\mathrm{P}_{\text {effectiv }} \mathrm{e}=\mathrm{p}$.

In contrast to this systematic selection procedure, if the $\mathrm{p}$ levels of factor A included in the experiment represents a random sample from the potential $\mathrm{p}$ levels, then the factor is considered to be random factor. In most practical situations in which random factors are encountered, $\mathrm{p}$ is quite small to relative to $\mathrm{P}$, and the ratio $\mathrm{p} / \mathrm{P}$ is quite close to zero.

The ratio of the number of levels of a factor in an experiment to the potential number of levels in the population is called the sampling fraction for a factor. In term of this sampling fraction, the definition of fixed and random factors may be summarized as mentioned in Table 1.

Table 1. Relationship between Sampling Fraction and Fixed Random Factors

\begin{tabular}{|c|c|}
\hline Sampling fraction & Factor \\
\hline $\mathrm{p} / \mathrm{P}$ or $\mathrm{p} / \mathrm{P}_{\text {effective }}=1$ & $\mathrm{~A}$ is a fixed factor \\
\hline $\mathrm{p} / \mathrm{P}=0$ & $\mathrm{~A}$ is a random factor \\
\hline
\end{tabular}

Cases in which the sampling fraction assumes a value between 0 and 1 do occur in practice. However, cases in which sampling fraction is either 1 or very close to 0 encountered more frequently. Main effects are defined in terms of parameters. Direct estimates of these parameters will be obtainable for corresponding statistics. 
The main effect for the level is the difference between the mean of all potential observations on the dependent variable at the level and grand mean of all potential observations.

The interaction between different levels is a measure of the extent to which the criterion mean for treatment combination cannot be predicted from the sum of the corresponding main effects. From many points of views, the interaction is a measure of the non-addivity of the main effects. To some extent the existence or non-existence of interaction depends upon the scale of measurement. For example, the interaction may not be present in terms of a logarithmic scale of measurement, whereas in terms of some other scale of measurement an interaction may be present. If alternative choices are present, then that scales which leads to the simplest additive model will generally provide the most complete and adequate summary of the experimental data.

\section{METHODOLOGY}

For this project, after conducting the related literature survey we found that the among the most important parameters were voltage, current, speed of arc travel and, nozzle to plate distance while keeping the wire diameter constant, which is $1.2 \mathrm{~mm}$ in this case. So these four variables were used as treatment variables for the model.

\subsection{Treatment Variables:}

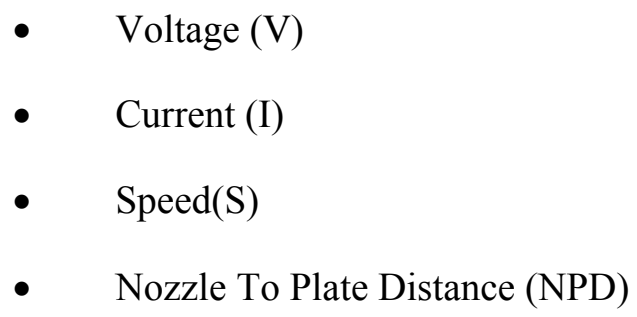

For conducting trial runs values or levels of these variables were chosen randomly from an infinite potential level i.e. the sampling fraction for these trials runs was equal to zero, however, we got a rough range of these factors from the literature we surveyed. With the help of these trials runs effective, representative's levels were developed for each factor (variables).

The numbers of levels for to be included in the experiment were chosen for each factor as per the design. These numbers of levels were two for each so as per the definition it is a $2^{\mathrm{n}}(2 * 2 * 2 * 2)$ factorial experiment. Where $\mathrm{n}$ is number of factors. If full factorial approach had been practiced, the number treatment combination would have been 16. But without affecting the accuracy of the model and the objective of the test we went for half factorial approach according to which the number of treatment combinations becomes $2^{\mathrm{n}-1}\left(2^{4-1}=2^{3}=8\right)$. The levels for each factor were the highest value and the lowest value of the factors in between and at which the outcome was acceptable. These values were outcomes of trials runs. Highest value has been represented by '+' and the lowest value has been represented by '-' as mentioned in Table 2. As per the design matrix the final runs were conducted and the response i.e. the weld deposit area was measured and noted down against each combination.

Then the values of different coefficients were calculated as per the modeling. These values of coefficients represent the significance of corresponding factors (variable) on the response. 
Higher the value of coefficients, higher the influence of the variable on the response. Negative value of coefficients indicates the inverse relationship between variable and response.

The calculation was done as per the following model.

\subsection{Design Matrix}

Table 2. Model Showing the treatment variables

\begin{tabular}{|c|c|c|c|c|}
\hline S. No. & $\begin{array}{l}\text { Voltage (V) } \\
\text { X1 }\end{array}$ & Current (I) X2 & Speed (S) X3 & $\begin{array}{l}\text { Nozzle to plate } \\
\text { difference (NPD) X4 }\end{array}$ \\
\hline 1. & + & + & + & + \\
\hline 2. & - & + & + & - \\
\hline 3. & + & - & + & - \\
\hline 4. & - & - & + & + \\
\hline 5. & + & + & - & - \\
\hline 6. & - & + & - & + \\
\hline 7. & + & - & - & + \\
\hline 8. & - & - & - & - \\
\hline
\end{tabular}

\subsection{Mathematical Model Developed}

Assuming the values of responses as $\mathrm{y}_{1}, \mathrm{y}_{2}, \mathrm{y}_{3}, \mathrm{y}_{4}, \mathrm{y}_{5}, \mathrm{y}_{6}, \mathrm{y}_{7}, \mathrm{y}_{8}$ against the treatment combinations 1, 2, 3, 4, 5, 6, 7, 8 respectively (as per the S. No. in the matrix design) $\mathrm{Y}$ as the optimized value of response (i.e. left hand side in the equation used for the showing the relation among the factors and the response).

Relation between main effects interactions effects and the response has been shown in the following equation:

$\mathrm{Y}=\mathrm{b}_{0}+\mathrm{b}_{1} \mathrm{X}_{1}+\mathrm{b}_{2} \mathrm{X}_{2}+\mathrm{b}_{3} \mathrm{X}_{3}+\mathrm{b}_{4} \mathrm{X}_{4}+\mathrm{b}_{12}\left(\mathrm{X}_{1} \mathrm{X}_{2}\right)+\mathrm{b}_{13}\left(\mathrm{X}_{1} \mathrm{X}_{3}\right)+\mathrm{b}_{14}\left(\mathrm{X}_{1} \mathrm{X}_{4}\right)+\mathrm{b}_{23}\left(\mathrm{X}_{2} \mathrm{X}_{3}\right)+$ $\mathrm{b}_{24}\left(\mathrm{X}_{2} \mathrm{X}_{4}\right)+\mathrm{b}_{34}\left(\mathrm{X}_{3} \mathrm{X}_{4}\right)$

Here $\mathrm{Y}$ is the optimized weld deposit area, $\mathrm{y}_{\mathrm{i}}(\mathrm{i}=1$ to 8$)$ is the response of the $\mathrm{i}^{\text {th }}$ treatment combination, $b_{0}$ is the mean of all the responses, $b_{j}(j=1$ to 4$)$ is the coefficient of $j_{\text {th }}$ main factor $(j$ $=1$ for voltage, 2 for current, 3 for speed, 4 for NPD), and $b_{j k}(j, k=1$ to 4$)$ is the coefficient for interaction factor. 
Values of all these coefficients were calculated as followings:
$\mathrm{b}_{0} \quad=\quad \sum \mathrm{y}_{\mathrm{i} / 8}$
$=\quad\left[\left(\mathrm{y}_{1}+\mathrm{y}_{2}+\mathrm{y}_{3}+\mathrm{y}_{4}+\mathrm{y}_{5}+\mathrm{y}_{6}+\mathrm{y}_{7}+\mathrm{y}_{8}\right)\right] / 8$
$\mathrm{b}_{1}=\left[\left(\mathrm{y}_{1}-\mathrm{y}_{2}+\mathrm{y}_{3-}-\mathrm{y}_{4}+\mathrm{y}_{5}-\mathrm{y}_{6}+\mathrm{y}_{7-} \mathrm{y}_{8}\right)\right] / 8$
$=\quad\left[\left(\mathrm{y}_{1}+\mathrm{y}_{3}+\mathrm{y}_{5}+\mathrm{y}_{7}\right)-\left(\mathrm{y}_{2}+\mathrm{y}_{4}+\mathrm{y}_{6}+\mathrm{y}_{8}\right)\right] / 8$
$\mathrm{b}_{2}=\left[\left(\mathrm{y}_{1}+\mathrm{y}_{2}-\mathrm{y}_{3}-\mathrm{y}_{4}+\mathrm{y}_{5}+\mathrm{y}_{6}-\mathrm{y}_{7-} \mathrm{y}_{8}\right)\right] / 8$
$\left[\left(\mathrm{y}_{1}+\mathrm{y}_{2}+\mathrm{y}_{5}+\mathrm{y}_{6}\right)-\left(\mathrm{y}_{3}+\mathrm{y}_{4}+\mathrm{y}_{7}+\mathrm{y}_{8}\right)\right] / 8$
$\mathrm{b}_{3}=\left[\left(\mathrm{y}_{1}+\mathrm{y}_{2}+\mathrm{y}_{3}+\mathrm{y}_{4}-\mathrm{y}_{5}-\mathrm{y}_{6}-\mathrm{y}_{7}-\mathrm{y}_{8}\right)\right] / 8$
$=\quad\left[\left(\mathrm{y}_{1}+\mathrm{y}_{2}+\mathrm{y}_{3}+\mathrm{y}_{4}\right)-\left(\mathrm{y}_{5}+\mathrm{y}_{6}+\mathrm{y}_{7}+\mathrm{y}_{8}\right)\right] / 8$
$\mathrm{b}_{4}=\left[\left(\mathrm{y}_{1-} \mathrm{y}_{2-} \mathrm{y}_{3}+\mathrm{y}_{4-}-\mathrm{y}_{5}-\mathrm{y}_{6}+\mathrm{y}_{7}-\mathrm{y}_{8}\right)\right] / 8$
$=\quad\left[\left(\mathrm{y}_{1}+\mathrm{y}_{4}+\mathrm{y}_{6}+\mathrm{y}_{7}\right)-\left(\mathrm{y}_{2}+\mathrm{y}_{3}+\mathrm{y}_{5}+\mathrm{y}_{8}\right] / 8\right.$
$\mathrm{b}_{12}=\left[\left(\mathrm{y}_{1-} \mathrm{y}_{2}+\mathrm{y}_{3}+\mathrm{y}_{4}+\mathrm{y}_{5}+\mathrm{y}_{6}+\mathrm{y}_{7}+\mathrm{y}_{8}\right)\right] / 8$
$=\quad\left[\left(\mathrm{y}_{1}+\mathrm{y}_{4}+\mathrm{y}_{5}+\mathrm{y}_{8}\right)-\left(\mathrm{y}_{2}+\mathrm{y}_{3}+\mathrm{y}_{6}+\mathrm{y}_{7}\right)\right] / 8$
$\mathrm{b}_{13}=\left[\left(\mathrm{y}_{1}-\mathrm{y}_{2}+\mathrm{y}_{3}-\mathrm{y}_{4}-\mathrm{y}_{5}+\mathrm{y}_{6}-\mathrm{y}_{7}+\mathrm{y}_{8}\right)\right] / 8$
$=\quad\left[\left(\mathrm{y}_{1}+\mathrm{y}_{3}+\mathrm{y}_{6}+\mathrm{y}_{8}\right)-\left(\mathrm{y}_{2}+\mathrm{y}_{4}+\mathrm{y}_{5}+\mathrm{y}_{7}\right)\right] / 8$
$\mathrm{b}_{14}=\left[\left(\mathrm{y}_{1}+\mathrm{y}_{2}-\mathrm{y}_{3}-\mathrm{y}_{5}-\mathrm{y}_{6}+\mathrm{y}_{7}+\mathrm{y}_{8}\right)\right] / 8$
$=\quad\left[\left(\mathrm{y}_{1}+\mathrm{y}_{2}+\mathrm{y}_{7}+\mathrm{y}_{8}\right)-\left(\mathrm{y}_{3}+\mathrm{y}_{4}+\mathrm{y}_{5}+\mathrm{y}_{6}\right)\right] / 8$
$\mathrm{b}_{23}=\left[\left(\mathrm{y}_{1}+\mathrm{y}_{2}-\mathrm{y}_{3}-\mathrm{y}_{4}-\mathrm{y}_{5}-\mathrm{y}_{6}+\mathrm{y}_{7}+\mathrm{y}_{8}\right)\right] / 8$
$=\quad\left[\left(\mathrm{y}_{1}+\mathrm{y}_{2}+\mathrm{y}_{7}+\mathrm{y}_{8}\right)-\left(\mathrm{y}_{3}+\mathrm{y}_{4}+\mathrm{y}_{5}+\mathrm{y}_{6}\right)\right] / 8$
$\mathrm{b}_{24}=\left[\left(\mathrm{y}_{1}-\mathrm{y}_{2}+\mathrm{y}_{3}-\mathrm{y}_{4}-\mathrm{y}_{5}+\mathrm{y}_{6}-\mathrm{y}_{7}+\mathrm{y}_{8}\right)\right] / 8$
$=\quad\left[\left(\mathrm{y}_{1}+\mathrm{y}_{3}+\mathrm{y}_{6}+\mathrm{y}_{8}\right)-\left(\mathrm{y}_{2}+\mathrm{y}_{4}+\mathrm{y}_{5}+\mathrm{y}_{7}\right)\right] / 8$
$\mathrm{b}_{34}=\left[\left(\mathrm{y}_{1}-\mathrm{y}_{2}-\mathrm{y}_{3}+\mathrm{y}_{4}+\mathrm{y}_{5}-\mathrm{y}_{6}-\mathrm{y}_{7}+\mathrm{y}_{8}\right)\right] / 8$
$=\left[\left(\mathrm{y}_{1}+\mathrm{y}_{4}+\mathrm{y}_{5}+\mathrm{y}_{8}\right)-\left(\mathrm{y}_{2}+\mathrm{y}_{3}+\mathrm{y}_{6}+\mathrm{y}_{7}\right)\right] / 8$ 


\section{RESULTS}

Using the half factorial approach following are the optimized values of treatment variables obtained as mentioned in Table 3.

Table 3. Optimized Gas Metal Arc Welding Parameters

\begin{tabular}{|c|c|c|c|c|c|}
\hline S. NO. & $\begin{array}{l}\text { Voltage (V) } \\
\text { in volts } X 1\end{array}$ & $\begin{array}{l}\text { Current (I) } \\
\text { in amperes X2 }\end{array}$ & $\begin{array}{l}\text { Speed (S) } \\
\text { mm/sec. X3 }\end{array}$ & $\begin{array}{l}\text { Nozzle to plate } \\
\text { difference } \\
\text { (NPD)mm X4 }\end{array}$ & $\begin{array}{l}\text { Response (WDA) } \\
\text { in } \mathrm{mm}^{2} \mathrm{Yi}\end{array}$ \\
\hline 1. & 22 & 160 & 5 & 20 & 21.8 \\
\hline 2. & 16 & 160 & 5 & 12 & 16.4 \\
\hline 3. & 22 & 100 & 5 & 12 & 28.9 \\
\hline 4. & 16 & 100 & 5 & 20 & 12.8 \\
\hline 5. & 22 & 160 & 2.43 & 12 & 17.4 \\
\hline 6. & 16 & 160 & 2.43 & 20 & 17.0 \\
\hline 7. & 22 & 100 & 2.43 & 20 & 29.3 \\
\hline 8. & 16 & 100 & 2.43 & 12 & 16.5 \\
\hline
\end{tabular}

Now as per the equations mentioned earlier the values of different effects can be calculated as below:
$\mathrm{b}_{0} \quad=\quad 20.0125$
$\mathrm{b}_{1}=-1.8625$
$\mathrm{b}_{2}=4.3375$
$\mathrm{b}_{3}=-0.0375$
$\mathrm{b}_{4}=0.2125$
$b_{12}=-2.8875$
$b_{13}=1.0750$
$\mathrm{b}_{14}=0.9875$
$\mathrm{b}_{23}=0.9875$ 
$\mathrm{b}_{24}=1.0750$

$\mathrm{b}_{34}=-2.8875$

So the actual model could be represented by following equation:

$\mathrm{Y}=20.0125+(-1.8625) \mathrm{X} 1+4.3375 \mathrm{X}_{2}+(-0.0375) \mathrm{X} 3+0.2125 \mathrm{X}_{4}(-2.8875)\left(\mathrm{X}_{1} \mathrm{X}_{2}\right)+$ $1.075\left(\mathrm{X}_{1} \mathrm{X}_{3}\right)+0.9875\left(\mathrm{X}_{1} \mathrm{X}_{4}\right)+0.9875\left(\mathrm{X}_{2} \mathrm{X}_{3}\right)+1.075\left(\mathrm{X}_{2} \mathrm{X}_{4}\right)+(-2.8875)\left(\mathrm{X}_{3} \mathrm{X}_{4}\right)$

The results of present investigation in shows the influence of treatment variables (Current, Voltage, NPD, Welding Speed) on welding deposition area (WDA) as shown in Fig. 1.

Fig. 1. Influence of Process Parameters on welding deposition area.

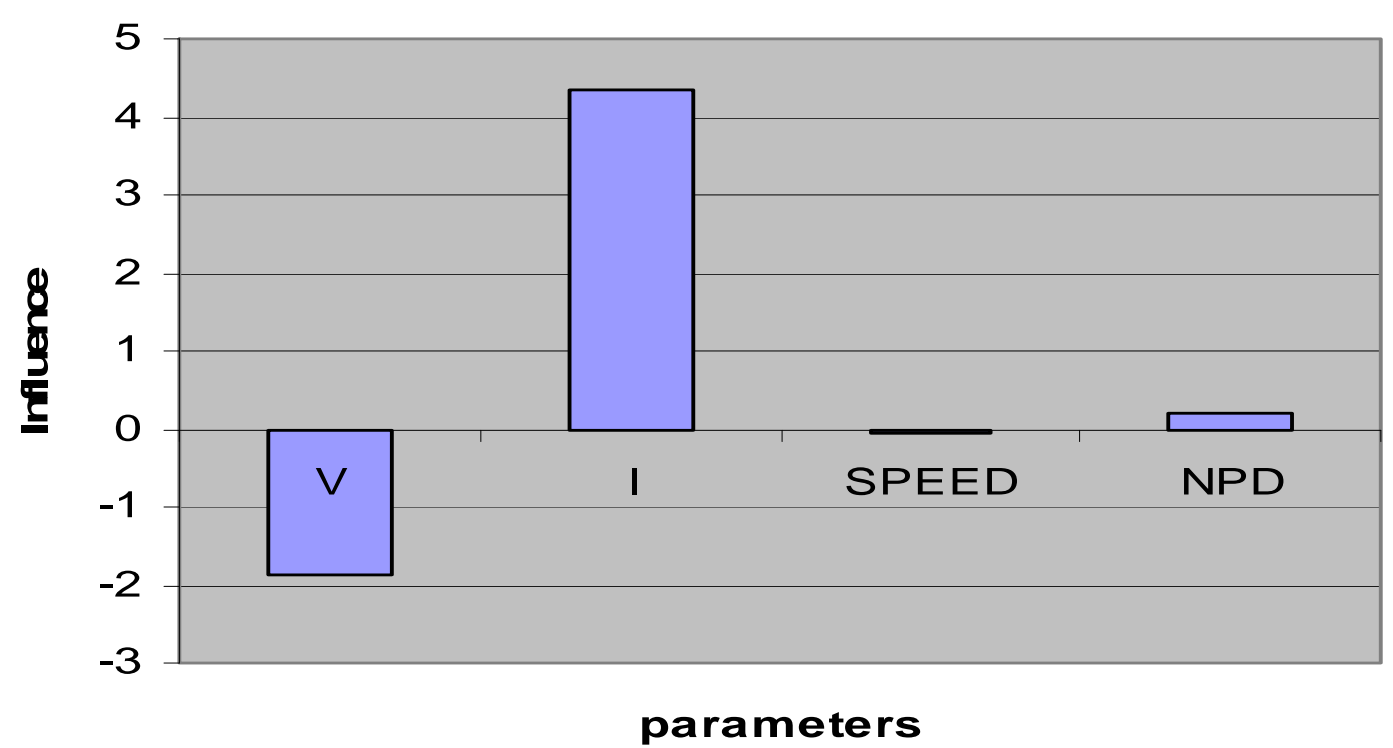

\section{CONCLUSIONS}

1. Results indicate that processes variables influence the weld bead area to a significant extent.

2. Various welding variables which influence WDA were identified and their quantitative influence on the same was investigated.

3. Welding current was found to be most influencing variable to WDA.

4. For a constant heat input, welds made using electrode negative polarity (DCEN), a small diameter electrode, long electrode extension, low voltage and low welding speed produce large bead area. 
5. The two level fractional half area fractional designs is found to be very effective tool for quantifying to main and interaction effects of variable on weld bead area.

6. The model is problem specific however the technique can be applied very effectively.

\section{ACKNOWLEDGEMENT}

The author acknowledges with thanks the support provided by Department of Mechanical Engineering, RIEIT, Railmajra, Distt. Nawanshahr (PB) India.

\section{REFERENCES}

1. E. Karadeniz, Ozsarac, U. and Yildiz, C., "The effect of process parameters on penetration in gas metal arc welding process", Materials and Design, 2007 , Vol 28 , Issue 2 , pp. 649-656.

2. M. Suban and J. Tusek, "Methods for the determination of arc stability", Journal of Materials Processing Technology, 2003, pp. 430-437.

3. T.P. Quinn, C. Smith, C.N. McCowan, E. Blachowiak, R.B. Madigan, "Arc Sensing for Defects in Constant-Voltage Gas Metal Arc Weldiing", Welding Journal, 1999, Vol. 78, pp. 322-328.

4. P. J. Hewitt and M. G. Madden, "Chromium in welding process parameters and hexavalent MIG Fume.”, Ann. Occup. Hyg.,1986, Vol. 30, No. 4, pp. 427-434.

5. K.C. Jang, D.G. Lee, J.M. Kuk and I.S. Kim, "Welding and environmental test condition effect in weldability and strength of Al alloy", Journal of Materials Processing Technology, 2005, Vol. 164-165, pp.1038-1045.

6. P. Praveen, P.K.D.V. Yarlagadda, "Meeting challenges in welding of aluminum alloys through pulse gas metal arc welding", Journal of Materials Processing Technology, 2005, pp.1106-1112.

7. J. M. Kuk, K. C. Jang, D. G. Lee, I. S. Kim, "Effects of temperature and shielding gas mixture on fatigue life of 5083 aluminum alloy", Journal of Materials Processing Technology, 2004, Vol. 155-156, , pp.1408-1414.

8. N. Murugan, R. S. Parmar, "Effects of MIG process parameters on the geometry of the bead in the automatic surfacing of stainless steel", Journal of Materials Processing Technology, 1994, Vol. 41, pp. 381-398.

9. P. Praveen, P.K.D.V. Yarlagadda, M.J. Kang, "Advancements in pulse gas metal arc welding”, Journal of Materials Processing Technology, Vol. 164-165, 2005, pp.11131119. 
10. L. Quintino and C.J. Allum, "Pulsed GMAW: interactions between process parameters part 1", Welding Met. Fabrication, Vol. 85, 1981, pp. 5-9.

11. S. Ueguri, K. Hara, H. Komura, "Study of metal transfer in pulsed GMA welding”, Weld. J., 1985, Vol. 64, pp. 242-50.

12. Z. Smati, Automated pulsed MIG welding, Metal Construction, 1985, Vol. 18, pp 38-44.

13. Y. S. Kim, "Metal transfer in gas metal arc welding”, PhD Thesis, 1989, MIT: USA.

14. J. H. Waszink, M. J. Piena, "Experimental investigation of drop detachment and drop velocity in GMAW”, Welding Journal, Vol. 65 ,1986, pp.289-98.

15. L. A. Jones, T. W. Eager, J. H. Lang, "Magnetic forces acting on molten drops in gas metal arc welding”, J. Phys. D. Appl. Phys., Vol. 31 ,1998, pp. 93-106.

16. J. H. Nixon, J. Norrish, "Determination of pulsed MIG process parameters", Welding and Metal Fabrication, 1988 , pp. 4-7.

17. F. Wang, W. K. Hou, S. J. Hu, E Kannatey-Asibu, W. W. Schultz, P. C. Wang, "Modelling and analysis of metal transfer in gas metal arc welding", J. Phys. D: Appl. Phys., Vol. 36 , 2003 , pp.1143-1152.

18. F. Zhu, "A comprehensive dynamic model of the gas metal arc welding process", $\mathrm{PhD}$ Thesis, 2003, University of Missouri- Rolla USA .

19. M. Goodarzi, "Mathematical modelling of gas tungsten arc welding (GTAW) and gas metal arc welding (GMAW) processes", PhD Thesis, 2003, University of Toronto Canada.

20. Ghosh P.K., Gupta S.R., Gupta P.C., Rathi R., "Fatigue characteristics of pulsed MIGwelded Al-Zn-Mg alloy”, Journal of Material Science, Vol. 26 , Issue 22 ,1991, pp. 6161-6170. 